\title{
Associations between Maternal Cadmium Exposure with Risk of Preterm Birth and Low Birth Weight: Effect of Mediterranean Diet Adherence on Affected Prenatal Outcomes
}

\author{
Sarah Gonzalez-Nahm ${ }^{1, *}$, Kiran Nihlani ${ }^{2}$, John S. House ${ }^{3}$, , Rachel L. Maguire ${ }^{4}$, \\ Harlyn G. Skinner ${ }^{4}$ and Cathrine Hoyo ${ }^{4}$ \\ 1 Department of Nutrition, University of Massachusetts Amherst, Amherst, MA 01003, USA \\ 2 Department of Statistics, University of Pittsburgh, Pittsburgh, PA 15260, USA; kiran.nihlani@pitt.edu \\ 3 National Institute of Environmental Health Sciences, Durham, NC 27709, USA; john.house@nih.gov \\ 4 Department of Biological Sciences, North Carolina State University, Raleigh, NC 27606, USA; \\ rlmaguir@ncsu.edu (R.L.M.); harlyn.skinner@ncsu.edu (H.G.S.); choyo@ncsu.edu (C.H.) \\ * Correspondence: snahm@umass.edu
}

Received: 15 September 2020; Accepted: 16 October 2020; Published: 20 October 2020

check for updates

\begin{abstract}
Prenatal cadmium exposure at non-occupational levels has been associated with poor birth outcomes. The intake of essential metals, such as iron and selenium, may mitigate cadmium exposure effects. However, at high levels, these metals can be toxic. The role of dietary patterns rich in these metals is less studied. We used a linear and logistic regression in a cohort of 185 mother-infant pairs to assess if a Mediterranean diet pattern during pregnancy modified the associations between prenatal cadmium exposure and (1) birth weight and (2) preterm birth. We found that increased cadmium exposure during pregnancy was associated with lower birth weight ( $\beta=-210.4 ; 95 \% \mathrm{CI}:-332.0,-88.8 ; p=0.008)$ and preterm birth (OR $=0.11 ; 95 \% \mathrm{CI}: 0.01,0.72$; $p=0.04)$; however, these associations were comparable in offspring born to women reporting high adherence to a Mediterranean $\operatorname{diet}(\beta=-274.95 ; 95 \% \mathrm{CI}:-701.17,151.26 ; p=0.20)$ and those with low adherence ( $\beta=-64.76 ; 95 \% \mathrm{CI}$ : $-359.90,230.37 ; p=0.66)$. While the small sample size limits inference, our findings suggest that adherence to a Mediterranean dietary pattern may not mitigate cadmium exposure effects. Given the multiple organs targeted by cadmium and its slow excretion rate, larger studies are required to clarify these findings.
\end{abstract}

Keywords: cadmium; heavy metals; birth weight; preterm birth; diet pattern; Mediterranean diet; pregnancy

\section{Introduction}

Although cadmium is a naturally occurring heavy metal, its increased use in numerous industrial applications has made it one of the most abundant environmental pollutants present in atmospheric, terrestrial, and aquatic systems [1,2]. Cadmium is classified as a probable carcinogen [3] and its lack of degradation in the environment facilitates its persistence and enables sustained human exposure [2,4]. While contaminated air from industrial processes is the most cited source of occupational exposure [2], non-occupational cadmium exposure can occur through the inhalation of tobacco smoke and dust. Cadmium is also present in some commercial fertilizers [5-8] and contamination of agricultural soils results in the ingestion of cadmium through dietary staples [2,4]. In the US and other regulated societies, dietary cadmium intake is estimated at $\sim 1 \mu \mathrm{g} /$ day $[1,9]$. The slow excretion of cadmium leads to accumulation in the body over time [4]. 
Early-life cadmium exposure in children and pregnant women has been associated with low birth weight (either due to growth restriction or shorter gestation) [10-13], childhood disorders including neurodevelopmental disorders, and indicators of metabolic dysfunction such as obesity-which have been recapitulated in zebrafish [14]. Low birth weight and preterm birth are public health concerns, as they are risk factors for early mortality and the onset of later disease and co-morbidities [15]. Approximately $8 \%$ of infants in the US are born with a low birth weight $(\leq 2500 \mathrm{~g})$ [16] and approximately $10 \%$ of infants are born preterm (prior to 37 weeks gestation) [17] with increased frequencies for African-American infants [17] The management of low birth weight and preterm birth and associated co-morbidities poses a large financial burden on families and the healthcare system [18].

Dietary supplementation with essential metals including iron, calcium and selenium, has been recommended by multiple environmental health agencies to mitigate the effects of cadmium exposure, in part because cadmium influx occurs with metal transporters for these essential metals [19-21]. However, appropriate doses are unclear, as these essential metals can be toxic at high doses [20,21]. Polyphenols and other antioxidants in the diet have also shown the potential to reduce the negative consequences of cadmium exposure $[20,21]$. As humans typically consume combinations of nutrients as a part of meals or whole foods, the study of dietary patterns is an important tool to understand how public health recommendations can help reduce the risk from prenatal cadmium exposure. The Mediterranean diet pattern which is characterized by a high intake of iron, selenium, and antioxidants can be easily studied and translated to public health guidelines. Maternal adherence to a Mediterranean diet during pregnancy has been found to be associated with a reduced risk of gestational diabetes [22], normal birth weight [23-26] and longer gestational age [26,27], as well as favorable behavioral patterns [28], and other positive child outcomes [26]. Although there is an abundance of evidence suggesting multiple health benefits from adhering to a Mediterranean diet pattern [29-33], the potential role of this diet in mitigating the effects of prenatal cadmium exposure and birth outcomes has not yet been described. These analyses aim to explore the effect measure modification of Mediterranean diet pattern adherence during pregnancy in the association between elevated prenatal cadmium exposure and birth outcomes, including birth weight and preterm birth, and exploratory analyses of the association between prenatal cadmium exposure and Apgar scores and infant ponderal index at birth.

\section{Materials and Methods}

We used data from participants of the Newborn Epigenetics Study (NEST), a cohort of women-infant dyads from central North Carolina. Enrollment details have been described elsewhere [34]. In brief, 1700 women enrolled during pregnancy between 2009 and 2011 at qualifying prenatal clinics. Women met the following inclusion criteria: 18 years of age or older, plan to deliver in one of two birthing facilities in Durham county, and English or Spanish speaking. We excluded women who planned to give up custody of their child and those who did not carry offspring to term. Of the 1700 enrolled, 1304 remained after additional exclusions ( $n=115$ experienced a fetal death, $n=281$ refused further participation or an inability to follow-up with the participant). We collected blood and obtained cadmium measures for the first $n=310$ women. Of the 310, $n=298$ had non-missing values for birth weight, and $n=185$ women completed a food frequency questionnaire (FFQ). The median gestational age at enrollment was 11-12 weeks. We have previously shown that the 310 mother-infant pairs in whom cadmium was measured did not vary significantly from the remainder of the cohort [14]. The $n=185$ on whom FFQ data were available also did not differ from the 310 with respect to sex, race/ethnicity and maternal obesity distribution $(p>0.05)$. Those included were, however, more likely to have a higher educational level and older maternal age at delivery $(p<0.05)$. These factors were adjusted for in the analysis. The women in our cohort were not significantly different with respect to covariates from the women in the overall NEST cohort $(p>0.05)$. This study was approved by the Duke University Institutional Review Board (\#Pro00014548) on 19 February 2020. 


\subsection{Cadmium Exposure}

We measured cadmium in whole blood for the first 310 enrolled women at a median gestation age of 12 weeks, using ICP-MS and methods previously described in detail $[11,13]$. Because cadmium co-occurs with other environmental pollutants [35], we also measured lead and arsenic. Briefly, we measured prenatal cadmium concentrations in whole blood donated at enrollment as nanograms per gram (ng/g; $1000 \mathrm{ng} / \mathrm{g}=1035 \mathrm{ng} / \mu \mathrm{L}$ ) of blood weight using well-accepted solution-based ICP-MS methods. We homogenized temperature equilibrated whole blood samples $(0.2 \mathrm{~mL})$ and pipetted them into a trace metal-clean test tube. We used a calibrated mass balance to confirm the samples gravimetrically to $\pm 0.001 \mathrm{mg}$, and we spiked samples with internal standards consisting of known quantities (10 and $1 \mathrm{ng} / \mathrm{g}$, respectively) of indium (In) and bismuth (Bi) (SCP Science, USA), used to correct for instrument drift. We then diluted the solutions with water purified to $18.2 \mathrm{M} \Omega / \mathrm{cm}$ resistance, which we will refer to as Milli-Q water (Millipore, Bedford, MA, USA) and acidified the solutions using ultra-pure $12.4 \mathrm{~mol} / \mathrm{L}$ hydrochloric acid to result in a final concentration of $2 \%$ hydrochloric acid (by volume). We prepared all standards, including aliquots of the certified NIST 955c, and procedural blanks using the same process. We measured Cd concentrations using a Perkin Elmer DRC II (Dynamic Reaction Cell) axial field ICP-MS at Duke School of the environment, Durham, NC, USA. Calibration standards used to assess metals in blood included aliquots of Milli-Q water, and NIST 955c SRM spiked with known quantities of each metal in a linear range from 0.025 to $10 \mathrm{ng} / \mathrm{g}$. We prepared standards from $1000 \mathrm{mg} / \mathrm{L}$ single element standards (SCP Science, USA). We calculated method detection limits (MDLs) consistent with the two-step approach using the t99SLLMV method (USEPA, 1993) at 99\% $\mathrm{CI}(t=3.71)$. The MDLs generated values of $0.006,0.005$, and $0.071 \mu \mathrm{g} / \mathrm{dL}$, for cadmium, lead and arsenic, respectively. The thresholds of detection (LODs) were $0.002,0.002$, and $0.022 \mu \mathrm{g} / \mathrm{dL}, \mathrm{for} \mathrm{Cd}, \mathrm{Pb}$ and As, respectively, and limits of quantification (LOQs) (according to Long and Winefordner, 1983) were $0.0007,0.0006$, and $0.0073 \mu \mathrm{g} / \mathrm{dL}$ for $\mathrm{Cd}, \mathrm{Pb}$, and As, respectively. The number of samples below the LOD for $\mathrm{Cd}, \mathrm{Pb}$, and As were two, two, and one, respectively.

\subsection{Mediterranean Diet}

We measured overall diet using a modified food frequency questionnaire (FFQ) [36] at enrollment. Women were asked to report their usual intake over the past 3 months, allowing us to capture the periconceptional period. We scored women's diets using the data-driven Mediterranean Diet Score (MDS) [37]. The MDS assesses adherence to a Mediterranean diet pattern based on the reported intake of foods that are deemed to be beneficial: fruit, vegetables, fish, dairy, whole grains, legumes, nuts, and monounsaturated fatty acids, and foods that are deemed detrimental: meat. We excluded alcohol from the diet score, as alcohol is not generally recommended during pregnancy and the reported alcohol intake in our cohort was low. Women who reported an intake of a beneficial foods at or above the median for the study population received a score of 1 and 0 otherwise. Those who reported an intake of detrimental foods below the median received a score of 1 or 0 otherwise. The MDS ranges from 0 to 9 , with 0 representing the lowest possible adherence to a Mediterranean diet pattern and 9 representing the highest adherence to a Mediterranean diet pattern. We assessed maternal Mediterranean diet adherence as low (MDS at or below 4) and high (MDS above 4).

\subsection{Birth Outcomes}

At delivery, we abstracted parturition data, including infant birth weight and gestational age, from medical records. We used standard definitions for low birth weight $(\leq 2500 \mathrm{~g})$ and preterm birth (<37 weeks). We assessed birth weight continuously and preterm birth categorically ( $>37$ weeks gestation/ $\leq 37$ weeks gestation). We assessed infant Apgar scores continuously (1-10), with a higher score reflecting a greater level of health at birth. We also assessed birth length $(\mathrm{cm})$, and derived the infant ponderal index (PI) at birth. PI is a measure of the proportionality of body growth and is calculated using the formula: weight $(\mathrm{g}) \times\left(100 /\right.$ length $\left.\left(\mathrm{cm}^{3}\right)\right)$. 


\subsection{Statistical Analysis}

We used a linear regression to assess the association between elevated cadmium exposure during pregnancy and birth weight, and a logistic regression to assess the association between elevated cadmium exposure and preterm birth. In our study, cadmium was severely right-skewed. Despite $\log$ transformation, the skewness did not improve (results using the continuous log Cd variables are available in Supplemental Tables S1 and S2). As cadmium exposure is ubiquitous, we assessed cadmium in quartiles and defined high cadmium exposure as having a cadmium blood level in the highest quartile (mean Cd (ng/g) per quartile: 25 th percentile: 0.12 , 50th percentile: 0.24 , 75 th percentile: 0.46 ). We identified potential confounders a priori based on the literature and substantive knowledge and selected a final set of confounders using Bayesian Information Criteria (BIC). We included prepregnancy BMI, smoking during pregnancy, and sex of the infant as confounders in our final models. In our analysis of birth weight, we also included gestational age as a confounder and in our analysis of preterm birth we included birth weight as a confounder in the model. We assessed effect measure modification by Mediterranean diet adherence by including an interaction term in our models and by stratification of high and low maternal Mediterranean diet adherence. Effect measure modification analyses are limited to the 185 women who completed first trimester FFQs and had cadmium measures available. We conducted supplemental analysis to explore possible changes in the association between prenatal cadmium exposure and birth outcomes using different cut points for high and low Mediterranean diet adherence. Additionally, we explored the association between prenatal cadmium exposure and (1) infant Apgar score, (2) infant ponderal index at birth.

\section{Results}

We present study participant demographic factors overall, and by birth weight (Table 1) and Mediterranean diet adherence (Table 2). Of the 298 women included in our sample, 36\% were Black, $28 \%$ were white, $32 \%$ were Latina or Hispanic, and $4 \%$ were of other race/ethnicities. Approximately one-quarter of women had a BMI of 30 or greater, and about $75 \%$ of obese women were either African American or Hispanic. Over half of our sample (55\%) had a high school diploma. Among infants in our study, $6 \%$ were born prior to 37 weeks gestation and $5.7 \%$ weighed $2500 \mathrm{~g}$ or less at birth. Approximately $20 \%$ of mothers in our study reported smoking during pregnancy. The median (IQR) of cadmium concentration in blood was $0.24(0.34) \mathrm{ug} / \mathrm{g}$ of blood weight, and MDS scores were normally distributed and ranged from 0 to 9 and approximately half of the women in our study had a score at or below 4 . Women who did not deliver a low birth weight infant were more likely to be white, non-smokers, and have a college degree.

\subsection{Cadmium Exposure and Birth Weight}

Results of the associations between cadmium and birth weight are summarized in Table 3. After adjustment for prepregnancy BMI, smoking during pregnancy, gestational age, and sex of the infant, we observed that the women in the highest quartile of cadmium exposure during the prenatal period had infants whose birth weights were $210 \mathrm{~g}$ lower $(\beta=-210.4 ; 95 \% \mathrm{CI}:-332.0,-88.8$; $p=0.008$ ) than those in the lower three quartiles. Further including other co-occurring metals, lead and arsenic, that also have been linked to lower birth weights did not alter these associations. We explored removing gestational age from these models, as it may be on the causal pathway. This somewhat attenuated the association, however, it remained statistically significant ( $\beta=-161.6 ; 95 \%$ CI: -311.3 , $-11.9 ; p=0.04)$. Further adjusting the co-occurrence of other metals, including lead or arsenic, did not materially alter these findings (data not shown). 
Table 1. Sociodemographic characteristics of study participants by birth weight.

\begin{tabular}{|c|c|c|c|}
\hline Characteristics & Overall & $\begin{array}{l}\text { Low Birth Weight } \\
\quad(<2500 \mathrm{~g})\end{array}$ & $\begin{array}{l}\text { Non-Low Birth } \\
\text { Weight }(\geq 2500 \mathrm{~g})\end{array}$ \\
\hline Ethnicity & N (\%) & $\mathrm{N}(\%)$ & $\mathrm{N}(\%)$ \\
\hline White & $84(28.2)$ & $3(17.6)$ & $81(28.8)$ \\
\hline Black & $108(36.2)$ & $11(64.7)$ & $97(34.5)$ \\
\hline Hispanic & $94(31.5)$ & $2(11.8)$ & $92(32.7)$ \\
\hline Other & $12(4)$ & $1(5.9)$ & $11(3.9)$ \\
\hline \multicolumn{4}{|l|}{ Maternal obesity before pregnancy } \\
\hline$<30$ & $219(73.5)$ & 13 (76.4) & $206(73.3)$ \\
\hline $30+$ & $76(25.5)$ & $4(23.5)$ & $72(25.6)$ \\
\hline Missing & $3(1.0)$ & - & $3(1.1)$ \\
\hline \multicolumn{4}{|l|}{ Sex } \\
\hline Male & $149(50.0)$ & $8(47.0)$ & $141(50.2)$ \\
\hline Female & $149(50.0)$ & $9(52.9)$ & $140(49.8)$ \\
\hline \multicolumn{4}{|l|}{ Gestational age at delivery } \\
\hline$<37$ weeks & $18(6.0)$ & $12(70.6)$ & $6(2.1)$ \\
\hline $37+$ weeks & $280(94.0)$ & $5(29.4)$ & $275(97.8)$ \\
\hline \multicolumn{4}{|l|}{ Cigarette smoking during pregnancy } \\
\hline No & $242(81.2)$ & $9(52.9)$ & $233(82.9)$ \\
\hline Yes & $46(15.4)$ & $8(47.1)$ & $38(13.5)$ \\
\hline Missing & $10(3.4)$ & - & $10(3.6)$ \\
\hline \multicolumn{4}{|l|}{ Maternal educational attainment } \\
\hline College Graduate and some college & $134(45.0)$ & $6(3.5)$ & $128(45.6)$ \\
\hline High school or less & $164(55.0)$ & $11(64.7)$ & $153(54.4)$ \\
\hline \multicolumn{4}{|l|}{ Cadmium categories } \\
\hline Low & $224(75.2)$ & $8(47.1)$ & $216(76.9)$ \\
\hline High & $74(24.8)$ & $9(52.9)$ & $65(23.1)$ \\
\hline \multicolumn{4}{|l|}{$\begin{array}{c}\text { Cadmium concentrations (Median and } \\
\text { interquartile range) }\end{array}$} \\
\hline $\mathrm{Cd}$ & $0.24(0.34)$ & $0.67(0.61)$ & $0.23(0.29)$ \\
\hline \multicolumn{4}{|l|}{ Mediterranean diet adherence } \\
\hline Low $(\leq 4)$ & $92(30.9)$ & $8(47.1)$ & $84(29.9)$ \\
\hline $\operatorname{High}(>4)$ & $92(30.9)$ & $3(17.6)$ & 89 (31.7) \\
\hline Missing & $114(38.2)$ & $6(35.3)$ & $108(38.4)$ \\
\hline
\end{tabular}

- No missing data in this category. 
Table 2. Sociodemographic characteristics of study participants by Mediterranean diet adherence.

\begin{tabular}{|c|c|c|c|}
\hline Characteristics & Overall & $\begin{array}{c}\text { Low } \\
\text { Mediterranean } \\
\text { Adherence }(\leq 4)\end{array}$ & $\begin{array}{c}\text { High } \\
\text { Mediterranean } \\
\text { Adherence (>4) }\end{array}$ \\
\hline Ethnicity & $\mathrm{N}(\%)$ & $\mathrm{N}(\%)$ & $\mathrm{N}(\%)$ \\
\hline White & $70(37.8)$ & $24(26.1)$ & $46(49.5)$ \\
\hline Black & $54(29.2)$ & $38(41.3)$ & $16(17.2)$ \\
\hline Hispanic & $51(27.6)$ & $26(28.2)$ & $25(26.9)$ \\
\hline Other & $10(5.4)$ & $4(4.3)$ & $6(6.4)$ \\
\hline \multicolumn{4}{|l|}{ Maternal obesity before pregnancy } \\
\hline$<30$ & $143(77.3)$ & $69(75.0)$ & $74(79.6)$ \\
\hline $30+$ & $41(22.2)$ & $22(23.9)$ & $19(20.4)$ \\
\hline Missing & $1(0.5)$ & $1(1.1)$ & - \\
\hline \multicolumn{4}{|l|}{ Sex } \\
\hline Male & $101(54.6)$ & $52(56.5)$ & $49(52.7)$ \\
\hline Female & $84(45.4)$ & $40(43.5)$ & $44(47.3)$ \\
\hline \multicolumn{4}{|l|}{ Gestational age at delivery } \\
\hline$<37$ weeks & $13(7.0)$ & $9(9.8)$ & $4(4.3)$ \\
\hline $37+$ weeks & $172(93.0)$ & $83(90.2)$ & $89(95.7)$ \\
\hline \multicolumn{4}{|l|}{ Cigarette smoking during pregnancy } \\
\hline No & $158(85.4)$ & $73(79.3)$ & $85(91.4)$ \\
\hline Yes & $22(11.9)$ & $16(17.4)$ & $6(6.5)$ \\
\hline Missing & $5(2.7)$ & $3(3.3)$ & $2(2.1)$ \\
\hline \multicolumn{4}{|l|}{ Maternal educational attainment } \\
\hline College Graduate and some college & $86(46.5)$ & $53(57.6)$ & $33(35.5)$ \\
\hline High school or less & 99 (53.5) & 39 (41.9) & $60(64.5)$ \\
\hline \multicolumn{4}{|l|}{ Birth Weight } \\
\hline$<2500 \mathrm{~g}$ & $11(6.0)$ & $8(8.7)$ & $3(3.2)$ \\
\hline $2500+$ grams & $173(93.5)$ & $84(91.3)$ & $89(95.7)$ \\
\hline Missing & $1(0.5)$ & - & $1(1.1)$ \\
\hline \multicolumn{4}{|l|}{ Cadmium categories } \\
\hline Low & $147(79.5)$ & $69(75.0)$ & $78(83.9)$ \\
\hline High & $38(20.5)$ & $23(25.0)$ & $15(16.1)$ \\
\hline \multicolumn{4}{|l|}{$\begin{array}{l}\text { Metal concentrations (Median and } \\
\text { interquartile range) }\end{array}$} \\
\hline $\mathrm{Cd}$ & $0.1892(0.34)$ & $0.2319(0.36)$ & $0.1723(0.21)$ \\
\hline
\end{tabular}

We also regressed gestational age at birth on cadmium exposure, controlling for the same covariates (Table 4). We found that preterm birth is marginally associated with prenatal cadmium exposure $(\beta=-0.11 ; 95 \%$ CI: $0.01,0.72 ; p=0.04)$ (Table 2$)$. We included birth weight as a confounder in our main analysis and explored the effect of removing it in a supplemental analysis. When birth weight was removed from the model, the association between elevated prenatal cadmium exposure and preterm birth was no longer statistically significant $(\beta=1.2 ; 95 \% \mathrm{CI}: 0.37,3.31 ; p=0.74)$. Again, further 
adjustment for the co-occurring metals, lead and arsenic, did not alter these findings, suggesting that growth restriction, rather than preterm birth, may be the major contributor to these birth outcomes.

Table 3. Regression coefficients and $95 \%$ confidence intervals for the association/relationship between, cadmium exposure and weight.

\begin{tabular}{|c|c|c|c|}
\hline Factor & $\beta$ & $95 \% \mathrm{CI}$ & $p$ \\
\hline Birth weight ${ }^{a}$ & -210.38 & $(-332.00,-88.78)$ & 0.0008 \\
\hline Birth weight, no gestational age ${ }^{d}$ & -161.596 & $(-311.33,-11.86)$ & 0.04 \\
\hline Birth weight, low Med adherence $(\leq 4)$ b & -64.76 & $(-359.89,230.37)$ & 0.66 \\
\hline Birth Weight, high Med adherence $(>4)^{c}$ & -126.46 & $(-453.14,200.22)$ & 0.44 \\
\hline
\end{tabular}

Table 4. Odds ratio and 95\% confidence intervals of the association between elevated prenatal cadmium exposure and preterm birth.

\begin{tabular}{cccc}
\hline Factor & Odds Ratio & $\mathbf{9 5 \% ~ C I ~}$ & $p$ \\
\hline Preterm birth $^{\mathrm{a}}$ & 0.11 & $(0.01,0.72)$ & 0.04 \\
\hline Preterm birth, no birth weight $^{\mathrm{d}}$ & 1.20 & $(0.37,3.31)$ & 0.74 \\
\hline Preterm birth, low Med adherence $(\leq 4) \mathrm{b}^{\mathrm{b}}$ & 0.07 & $(0.0008,1.31)$ & 0.14 \\
\hline${\text { Preterm birth, high Med adherence }(>4)^{\mathrm{c}}}^{\mathrm{C}}$ & 0.01 & $(0,1.59)$ & 0.20 \\
\hline
\end{tabular}

${ }^{a}$ Adjusted for smoking during pregnancy, prepregnancy BMI, birth weight and sex of the infant. ${ }^{b}$ Adjusted for smoking during pregnancy, prepregnancy BMI, birth weight and sex of the infant, among mothers with a Mediterranean diet score at or below $4 .{ }^{c}$ Adjusted for smoking during pregnancy, prepregnancy BMI, birth weight and sex of the infant, among mothers with a Mediterranean diet score above $4 .{ }^{\mathrm{d}}$ Adjusted for smoking during pregnancy, prepregnancy BMI, and sex of the infant.

\subsection{Stratification by Mediterranean Diet Adherence}

To determine whether these associations were modified by adherence to a Mediterranean diet pattern, we first dichotomized the MDS below the median (a score of 4 of 9) among the $n=185$ of 310 pregnant women who also completed the food frequency questionnaire. We examined cadmium-birth outcome associations among low and high adherers to the Mediterranean diet. We found no evidence for effect measure modification by Mediterranean diet adherence in the association between prenatal cadmium exposure and either gestational age or birth weight. Among women who reported high adherence to a Mediterranean diet pattern during pregnancy, the magnitude of the association between prenatal cadmium exposure and birth weight $(\beta=-126.46$; $95 \%$ CI: -453.14 , 200.22; $p=0.44$ ) was indistinguishable from the $\beta=-210.38$ observed among all participants. Similarly, the association between prenatal cadmium exposure and birth weight among women with low Mediterranean adherence was not statistically significant ( $\beta=-64.76$; $95 \%$ CI: $-359.90,230.37 ; p=0.66$ ) (Table 3). However, these risk estimates lacked precision as confidence intervals were wide. We also observed no evidence for effect measure modification by maternal Mediterranean diet adherence on the association between prenatal cadmium exposure and preterm birth (high adherence: $\beta: 0.01$; 95\% CI: $0,1.59 ; p=0.20$; low adherence: $\beta: 0.07 ; 95 \%$ CI: $0.0008,1.31 ; p=0.14$ ) (Table 4). As expected from stratified analyses, including the interaction term of the Mediterranean diet adherence score and cadmium exposure did not alter these findings. The p-values for the interaction terms of cadmium and MDS in the overall birthweight or preterm birth models were not significant $(p>0.15)$. Defining "high Mediterranean adherence" with a more stringent cut-off of MDS of 5, 6 or 7 did alter these findings (data not shown). 


\subsection{Exploratory Analyses: Apgar Scores and PI}

In our exploratory analyses we found no association between elevated prenatal cadmium exposure and Apgar scores $(\beta=-0.009$; 95\% CI: $-0.13,0.12 ; p=0.89)$ or PI $(\beta=-0.03$; 95\% CI: $-0.11,0.06$; $p=0.51)$. Results available in Supplemental Table S3.

\section{Discussion}

Understanding the effects of cadmium in early life is important, as this toxic metal is ubiquitous in the environment. With no set upper threshold for children, the accepted tolerable limits based on body weight are likely detrimental to children whose body weight is also smaller. In these analyses, we evaluated the extent to which adherence to a Mediterranean diet modified the association of cadmium and poor birth outcomes. We found that elevated prenatal cadmium exposure was associated with a lower birth weight compared to infants born to mothers with average or low cadmium exposure during pregnancy. These associations persisted after further adjusting for other co-occurring toxic metals that have been previously associated with these poor birth outcomes. Furthermore, after removing gestational age as a confounder, the association between prenatal cadmium exposure and birth weight remained significant. However, the association between prenatal cadmium exposure and preterm birth lost significance after removing birth weight. We found no association between prenatal cadmium exposure and Apgar score or infant PI at birth.

Our findings are consistent with previous data from our group and others that have demonstrated that prenatal exposure to cadmium, at non-occupational levels, is associated with lower birth weight [10-12] and is not associated with preterm birth [10,38]. These findings are, however, not consistent with the hypothesis that dietary patterns rich in iron, selenium, and folate may mitigate exposure. We did not find evidence to support our hypothesis that adherence to a Mediterranean diet prenatally modifies the associations between cadmium exposure and poor birth outcomes, regardless of the cut-off used to define "high Mediterranean adherence". While sample size limits inference, these data suggest that, in this population, at these cadmium levels, adherence to a Mediterranean dietary pattern may not modify the effects of prenatal cadmium exposure on birth outcomes. We were also interested in understanding whether the association between prenatal cadmium exposure and adverse birth outcomes was related to growth restriction or shortened gestation. In our exploratory analysis, the association between cadmium exposure and birth weight remained significant after excluding gestational age from the model; however, the association between cadmium exposure and preterm birth was no longer significant after excluding birth weight. This suggests that cadmium exposure may influence birth weight through growth restriction rather than shortened gestation.

To our knowledge, this is the first attempt to determine the effects of the Mediterranean diet on the association between prenatal cadmium concentrations and documented poor birth outcomes in humans. Previous animal- and cell-based studies have shown that a dietary intake of iron, calcium, selenium, and folate can reduce toxicity from cadmium exposure [20,21]. The Mediterranean diet pattern has been found to be a rich source of iron, folate, and selenium [39]. Thus, our analysis showing that adherence to a Mediterranean diet pattern during pregnancy did not change the association between prenatal cadmium exposure and birth weight or preterm birth was surprising. The average intake of selenium in the US is high at $108.5 \mathrm{mcg} / \mathrm{day}$ [40], the intake of iron and calcium from food is lower than recommended at 11.5-13.7 mg/day [40] and 748 to $968 \mathrm{mg} /$ day (females) [41], respectively, and the intake of folate is insufficient for pregnancy at $455 \mathrm{mcg}$ DFE/day (females) [40]. It is possible that usual eating patterns in the US may not provide sufficient amounts of these nutrients to mitigate elevated cadmium exposure; therefore, diet interventions that encourage following a diet pattern with higher levels of iron, calcium, and folate may be warranted. Interventions focused on dietary modifications may hold better prospects for implementation and adherence in exposed populations when compared to interventions focused on costly landscape remediation. Additionally, dietary intervention does not carry the health risks associated with cadmium chelation using agents such as EDTA. 
The inability to find associations could be due to one of several possibilities, some related to how cadmium is estimated, and others related to the measurement of diet. For example, maternal circulating levels of cadmium may not reflect cadmium levels that the offspring may be exposed to, as there is evidence in support of cadmium being sequestered by the placenta [42]. Secondly, because in the United States the main source of cadmium in the diet is lettuce, milk and cookies [43], it is possible that the additional exposure to cadmium may overwhelm the nutritive benefits of this diet. It is also possible that women's intake in our sample may not represent a true Mediterranean diet pattern, even at high MDS values, as food choices and availability may differ by country [44]. Additionally, it may be that adherence to a Mediterranean diet pattern does reduce the effects of cadmium exposure on lower birth weight, yet we were underpowered to detect the associations. Although we were unable to establish a modifying effect of Mediterranean diet on the association between prenatal cadmium exposure and birth outcomes, the Mediterranean diet has been shown to protect against a number of diseases and inflammatory processes in the body [45], thus providing a rationale for its continued study. Given the ubiquity of this toxic metal in the environment, the effects of cadmium on birth outcomes, and the plausibility that a Mediterranean diet may mitigate the adverse effects, repeating these analyses in larger data sets is warranted.

Our study findings should be interpreted in the context of the study limitations. In addition to being underpowered to detect a significant effect measure modification that may have existed, both the measurement of Mediterranean diet adherence and our inability to "remove" the effects of dietary items such as lettuce and milk, which are major sources of cadmium in the US, is a limitation. An analysis of these relationships in different populations may clarify these findings. Furthermore, although implausible values were excluded from analyses, the Mediterranean diet was computed from self-reported diet data, which may have led to misclassified food intake that may be further biased by social desirability. This may have led to the under-reporting of unhealthy foods and the over-reporting of healthy foods. An additional limitation is the use of the MDS to assess diet. Although widely used and associated with a number of health outcomes, the MDS does not assess many foods that are thought to be "detrimental", such as sugar or highly processed convenience foods.

Despite this, our study also exhibits strengths. We used prospectively collected data, therefore we can establish the timing of exposure, modifiers, and outcomes. Another important strength of this study is that it assessed maternal dietary patterns rather than the intake of single nutrients. Humans consume most of their nutrients through foods and combinations of nutrients, therefore it is important to assess the role of dietary patterns in the potential mitigation of negative consequences from toxic exposures.

\section{Conclusions}

These limitations notwithstanding, this study contributes to the growing literature on the effects of toxic exposures during pregnancy and adds information on the potential role of diet in preventing adverse birth outcomes. Although our study did not support that maternal adherence to a Mediterranean diet pattern may mitigate exposure, it is possible that other dietary patterns may in fact help mitigate the association between elevated prenatal cadmium exposure and lower birth weights. Future research should focus on finding dietary patterns that can mitigate prenatal cadmium risk and that can be easily translatable into public health recommendations.

Supplementary Materials: The following are available online at http://www.mdpi.com/2305-6304/8/4/90/s1, Table S1: Regression coefficients and 95\% confidence intervals for the association/relationship between, cadmium exposure $(\log \mathrm{cd})$ and birth weight; Table S2: Odds ratio and 95\% confidence intervals for the association/relationship between cadmium exposure (log cd) and preterm birth; Table S3: Regression coefficients and 95\% confidence intervals for the association/relationship between, cadmium exposure (high/low) and (1) Apgar score, (2) Ponderal index.

Author Contributions: Conceptualization, C.H. and S.G.-N.; methodology and analysis, C.H., K.N, S.G.-N.; writing-original draft preparation, S.G.-N. and C.H.; writing-review and editing, S.G.-N., K.N., J.S.H., R.L.M., H.G.S., C.H.; funding acquisition, C.H. All authors have read and agreed to the published version of the manuscript. 
Funding: This research was funded by grant R24ES028531, R01MD011746 andP30ES025128, and supported in part by the division of intramural research at NIH, National Institute of Environmental Health Sciences.

Acknowledgments: The authors thank participants of the NEST study and Cheyenne Bradford for her help with the literature review.

Conflicts of Interest: The authors declare no conflict of interest.

\section{References}

1. World Health Organization. Cadmium; World Health Organization: Geneva, Switzerland, 1992.

2. United States Department of Health and Human Services; Agency for Toxic Substances and Disease Registry. Toxicological Profile for Cadmium; Centers for Disease Control and Prevention: Atlanta, GA, USA, 2012.

3. Straif, K.; Benbrahim-Tallaa, L.; Baan, R.; Grosse, Y.; Secretan, B.; El Ghissassi, F.; Bouvard, V.; Guha, N.; Freeman, C.; Galichet, L.; et al. A review of human carcinogens-Part C: Metals, arsenic, dusts, and fibres. Lancet Oncol. 2009, 10, 453-454. [CrossRef]

4. Satarug, S. Dietary Cadmium Intake and Its Effects on Kidneys. Toxics 2018, 6, 15. [CrossRef] [PubMed]

5. Webb, S.F. Simultaneous Determination of Arsenic, Cadmium, Calcium, Chromium, Cobalt, Copper, Iron, Lead, Magnesium, Manganese, Molybdenum, Nickel, Selenium, and Zinc in Fertilizers by Microwave Acid Digestion and Argon Inductively Coupled Plasma-Optical Emission Spectrometry Detection: Single-Laboratory Validation, First Action 2017.02. J. AOAC Int. 2018, 101, 383-384. [CrossRef] [PubMed]

6. Xu, Y.; Tang, H.; Liu, T.; Li, Y.; Huang, X.; Pi, J. Effects of long-term fertilization practices on heavy metal cadmium accumulation in the surface soil and rice plants of double-cropping rice system in Southern China. Environ. Sci. Pollut. Res. Int. 2018, 25, 19836-19844. [CrossRef]

7. Dharma-Wardana, M.W.C. Fertilizer usage and cadmium in soils, crops and food. Environ. Geochem. Health 2018, 40, 2739-2759. [CrossRef]

8. Rao, Z.X.; Huang, D.Y.; Wu, J.S.; Zhu, Q.H.; Zhu, H.H.; Xu, C.; Xiong, J.; Wang, H.; Duan, M.M. Distribution and availability of cadmium in profile and aggregates of a paddy soil with 30-year fertilization and its impact on Cd accumulation in rice plant. Environ. Pollut. 2018, 239, 198-204. [CrossRef]

9. World Health Organization. Cadmium Chapter 6.3. Air Quality Guidelines; World Health Organization: Geneva, Switzerland, 2000.

10. Johnston, J.E.; Valentiner, E.; Maxson, P.; Miranda, M.L.; Fry, R.C. Maternal cadmium levels during pregnancy associated with lower birth weight in infants in a North Carolina cohort. PLoS ONE 2014, 9, e109661. [CrossRef]

11. Vidal, A.C.; Semenova, V.; Darrah, T.; Vengosh, A.; Huang, Z.; King, K.; Nye, M.D.; Fry, R.; Skaar, D.; Maguire, R.; et al. Maternal cadmium, iron and zinc levels, DNA methylation and birth weight. BMC Pharmacol. Toxicol. 2015, 16, 20. [CrossRef]

12. Lin, C.M.; Doyle, P.; Wang, D.; Hwang, Y.H.; Chen, P.C. Does prenatal cadmium exposure affect fetal and child growth? Occup. Environ. Med. 2011, 68, 641-646. [CrossRef]

13. Wang, H.; Liu, L.; Hu, Y.F.; Hao, J.H.; Chen, Y.H.; Su, P.Y.; Yu, Z.; Fu, L.; Tao, F.B.; Xu, D.X. Association of maternal serum cadmium level during pregnancy with risk of preterm birth in a Chinese population. Environ. Pollut. 2016, 216, 851-857. [CrossRef]

14. Green, A.J.; Hoyo, C.; Mattingly, C.J.; Luo, Y.; Tzeng, J.Y.; Murphy, S.K.; Buchwalter, D.B.; Planchart, A. Cadmium exposure increases the risk of juvenile obesity: A human and zebrafish comparative study. Int. J. Obes. 2018, 42, 1285-1295. [CrossRef] [PubMed]

15. Gluckman, P.D.; Hanson, M.A.; Cooper, C.; Thornburg, K.L. Effect of in utero and early-life conditions on adult health and disease. N. Engl. J. Med. 2008, 359, 61-73. [CrossRef]

16. Martin, J.A.; Hamilton, B.E.; Osterman, M.J.K. Births in the United States, 2018. NCHS Data Brief 2019, 346, 1-8.

17. Martin, J.A.; Osterman, M.J.K. Describing the Increase in Preterm Births in the United States, $2014-2016$. NCHS Data Brief 2018, 312, 1-8.

18. Beam, A.L.; Fried, I.; Palmer, N.; Agniel, D.; Brat, G.; Fox, K.; Kohane, I.; Sinaiko, A.; Zupancic, J.A.F.; Armstrong, J. Estimates of healthcare spending for preterm and low-birthweight infants in a commercially insured population: 2008-2016. J. Perinatol. 2020, 40, 1091-1099. [CrossRef] [PubMed]

19. Genchi, G.; Sinicropi, M.S.; Lauria, G.; Carocci, A.; Catalano, A. The Effects of Cadmium Toxicity. Int. J. Environ. Res. Public Health 2020, 17, 3782. [CrossRef] [PubMed] 
20. Zwolak, I. The Role of Selenium in Arsenic and Cadmium Toxicity: an Updated Review of Scientific Literature. Biol. Trace Elem. Res. 2020, 193, 44-63. [CrossRef]

21. Zhai, Q.; Narbad, A.; Chen, W. Dietary strategies for the treatment of cadmium and lead toxicity. Nutrients 2015, 7, 552-571. [CrossRef]

22. Mijatovic-Vukas, J.; Capling, L.; Cheng, S.; Stamatakis, E.; Louie, J.; Cheung, N.W.; Markovic, T.; Ross, G.; Senior, A.; Brand-Miller, J.C.; et al. Associations of Diet and Physical Activity with Risk for Gestational Diabetes Mellitus: A Systematic Review and Meta-Analysis. Nutrients 2018, 10, 698. [CrossRef] [PubMed]

23. Timmermans, S.; Steegers-Theunissen, R.P.; Vujkovic, M.; den Breeijen, H.; Russcher, H.; Lindemans, J.; Mackenbach, J.; Hofman, A.; Lesaffre, E.E.; Jaddoe, V.V.; et al. The Mediterranean diet and fetal size parameters: the Generation R Study. Br. J. Nutr. 2012, 108, 1399-1409. [CrossRef]

24. Parlapani, E.; Agakidis, C.; Karagiozoglou-Lampoudi, T.; Sarafidis, K.; Agakidou, E.; Athanasiadis, A.; Diamanti, E. The Mediterranean diet adherence by pregnant women delivering prematurely: Association with size at birth and complications of prematurity. J. Matern-Fetal Neonatal Med. 2019, 32, 1084-1091. [CrossRef]

25. Chatzi, L.; Mendez, M.; Garcia, R.; Roumeliotaki, T.; Ibarluzea, J.; Tardón, A.; Amiano, P.; Lertxundi, A.; Iñiguez, C.; Vioque, J.; et al. Mediterranean diet adherence during pregnancy and fetal growth: INMA (Spain) and RHEA (Greece) mother-child cohort studies. Br. J. Nutr. 2012, 107, 135-145. [CrossRef] [PubMed]

26. Biagi, C.; Nunzio, M.D.; Bordoni, A.; Gori, D.; Lanari, M. Effect of Adherence to Mediterranean Diet during Pregnancy on Children's Health: A Systematic Review. Nutrients 2019, 11, 997. [CrossRef] [PubMed]

27. Peraita-Costa, I.; Llopis-Gonzalez, A.; Perales-Marin, A.; Diago, V.; Soriano, J.M.; Llopis-Morales, A.; Morales-Suarez-Varela, M. Maternal profile according to Mediterranean diet adherence and small for gestational age and preterm newborn outcomes. Public Health Nutr. 2020, 29, 1-13. [CrossRef] [PubMed]

28. House, J.S.; Mendez, M.; Maguire, R.L.; Gonzalez-Nahm, S.; Huang, Z.; Daniels, J.; Murphy, S.K.; Fuemmeler, B.F.; Wright, F.A.; Hoyo, C. Periconceptional Maternal Mediterranean Diet Is Associated With Favorable Offspring Behaviors and Altered CpG Methylation of Imprinted Genes. Front. Cell Dev. Biol. 2018, 6, 107. [CrossRef] [PubMed]

29. Martinez-Gonzalez, M.A.; Salas-Salvado, J.; Estruch, R.; Corella, D.; Fito, M.; Ros, E.; Predimed, I. Benefits of the Mediterranean Diet: Insights From the PREDIMED Study. Prog. Cardiovasc. Dis. 2015, 58, 50-60. [CrossRef] [PubMed]

30. Sofi, F.; Abbate, R.; Gensini, G.F.; Casini, A. Accruing evidence on benefits of adherence to the Mediterranean diet on health: An updated systematic review and meta-analysis. Am. J. Clin. Nutr. 2010, 92, 1189-1196. [CrossRef]

31. Chatzi, L.; Rifas-Shiman, S.L.; Georgiou, V.; Joung, K.E.; Koinaki, S.; Chalkiadaki, G.; Margioris, A.; Sarri, K.; Vassilaki, M.; Vafeiadi, M.; et al. Adherence to the Mediterranean diet during pregnancy and offspring adiposity and cardiometabolic traits in childhood. Pediatric Obes. 2017, 12 (Suppl. 1), 47-56. [CrossRef] [PubMed]

32. Chatzi, L.; Garcia, R.; Roumeliotaki, T.; Basterrechea, M.; Begiristain, H.; Iniguez, C.; Vioque, J.; Kogevinas, M.; Sunyer, J. Mediterranean diet adherence during pregnancy and risk of wheeze and eczema in the first year of life: INMA (Spain) and RHEA (Greece) mother-child cohort studies. Br. J. Nutr. 2013, 110, 2058-2068. [CrossRef]

33. Sofi, F.; Macchi, C.; Abbate, R.; Gensini, G.F.; Casini, A. Mediterranean diet and health status: An updated meta-analysis and a proposal for a literature-based adherence score. Public Health Nutr. 2014, 17, 2769-2782. [CrossRef]

34. Liu, Y.; Murphy, S.K.; Murtha, A.P.; Fuemmeler, B.F.; Schildkraut, J.; Huang, Z.; Overcash, F.; Kurtzberg, J.; Jirtle, R.; Iversen, E.S.; et al. Depression in pregnancy, infant birth weight and DNA methylation of imprint regulatory elements. Epigenetics 2012, 7, 735-746. [CrossRef] [PubMed]

35. Iwai-Shimada, M.; Kameo, S.; Nakai, K.; Yaginuma-Sakurai, K.; Tatsuta, N.; Kurokawa, N.; Nakayama, S.F.; Satoh, H. Exposure profile of mercury, lead, cadmium, arsenic, antimony, copper, selenium and zinc in maternal blood, cord blood and placenta: the Tohoku Study of Child Development in Japan. Environ. Health Prev. Med. 2019, 24, 35. [CrossRef] [PubMed]

36. Gonzalez-Nahm, S.; Mendez, M.A.; Robinson, W.R.; Murphy, S.K.; Hoyo, C.; Hogan, V.K.; Rowley, D.L. Low maternal adherence to a Mediterranean diet is associated with increase in methylation at the MEG3-IG differentially methylated region in female infants. Environ. Epigenet. 2017, 3, 1-10. [CrossRef] [PubMed]

37. Trichopoulou, A.; Costacou, T.; Bamia, C.; Trichopoulos, D. Adherence to a Mediterranean diet and survival in a Greek population. N. Engl. J. Med. 2003, 348, 2599-2608. [CrossRef] [PubMed] 
38. Yildirim, E.; Derici, M.K.; Demir, E.; Apaydin, H.; Kocak, O.; Kan, O.; Gorkem, U. Is the Concentration of Cadmium, Lead, Mercury, and Selenium Related to Preterm Birth? Biol. Trace Elem. Res. 2019, 191, 306-312. [CrossRef] [PubMed]

39. Serra-Majem, L.; Bes-Rastrollo, M.; Roman-Vinas, B.; Pfrimer, K.; Sanchez-Villegas, A.; Martinez-Gonzalez, M.A. Dietary patterns and nutritional adequacy in a Mediterranean country. Br. J. Nutr. 2009, 101 (Suppl. 2), S21-S28. [CrossRef] [PubMed]

40. U.S. Department of Agriculture, Agricultural Research Service. What We Eat in America: NHANES 2013-2014; U.S. Department of Agriculture: Beltsville, MD, USA, 2016.

41. Bailey, R.L.; Dodd, K.W.; Goldman, J.A.; Gahche, J.J.; Dwyer, J.T.; Moshfegh, A.J.; Sempos, C.T.; Picciano, M.F. Estimation of total usual calcium and vitamin D intakes in the United States. J. Nutr. 2010, 140, 817-822. [CrossRef]

42. Needham, L.L.; Grandjean, P.; Heinzow, B.; Jørgensen, P.J.; Nielsen, F.; Patterson, D.G., Jr.; Sjödin, A.; Turner, W.E.; Weihe, P. Partition of environmental chemicals between maternal and fetal blood and tissues. Environ. Sci. Technol. 2011, 45, 1121-1126. [CrossRef]

43. Kim, K.; Melough, M.M.; Vance, T.M.; Noh, H.; Koo, S.I.; Chun, O.K. Dietary Cadmium Intake and Sources in the US. Nutrients 2018, 11, 2. [CrossRef]

44. Hoffman, R.; Gerber, M. Evaluating and adapting the Mediterranean diet for non-Mediterranean populations: A critical appraisal. Nutr. Rev. 2013, 71, 573-584. [CrossRef]

45. Mentella, M.C.; Scaldaferri, F.; Ricci, C.; Gasbarrini, A.; Miggiano, G.A.D. Cancer and Mediterranean Diet: A Review. Nutrients 2019, 11, 2059. [CrossRef] [PubMed]

Publisher's Note: MDPI stays neutral with regard to jurisdictional claims in published maps and institutional affiliations.

(C) 2020 by the authors. Licensee MDPI, Basel, Switzerland. This article is an open access article distributed under the terms and conditions of the Creative Commons Attribution (CC BY) license (http://creativecommons.org/licenses/by/4.0/). 